\title{
Retraction Note to: On the Illuminationist Approach to Imaginal Power: Outline of a Perspective
}

\author{
Mahmoud Khatami
}

Published online: 6 February 2015

(C) Springer Science+Business Media Dordrecht 2015

Retraction Note to: Topoi (2007) 26:221-229

DOI 10.1007/s11245-007-9015-y

The author has retracted this article published in Topoi Volume 26, Issue 2, pages 221-229, DOI: 10.1007/s11245007-9015-y because it contains passages from the previously published manuscript by Mikel Dufrenne The Phenomenology of Aesthetic Experience (Northwestern University Press, 1973), without acknowledging the source. The author apologizes to the Journal and readers as well as the author of the original work.

The online version of the original article can be found under doi:10.1007/s11245-007-9015-y.

M. Khatami ( $\square)$

The University of Tehran, 16 Azar Street, Enghelab Ave., Tehran, Iran

e-mail: mahmoud.khatami@gmail.com 